\title{
LA IDENTIDAD RELACIONAL Y EL PRINCIPIO DE SOLIDARIDAD COMO BASES PARA LA EDUCACIÓN INTERCULTURAL
}

\author{
Relational identity and principle of solidarity as the bases \\ for the intercultural education
}

\section{L'identité relationnelle et le principe de solidarité en tant que bases pour une éducation interculturelle}

\author{
Nuria GARRO-GIL y Sarah CARRICA-OCHOA \\ Universidad de Navarra. Facultad de Filosofía y Letras. Departamento de \\ Educación. Campus Universitario, Edificio de Bibliotecas. 31009 Pamplona, \\ Navarra (España).Correo-e:nggil@alumni.unav.es; scarrica@alumni.unav.es
}

Fecha de recepción: marzo de 2013

Fecha de aceptación: junio de 2013

Biblid [(1130-3743) 25, 2-2013, 133-154]

\section{RESUMEN}

Una vez constatado el fracaso del multiculturalismo y de todas sus variantes teórico-prácticas para el estudio, análisis y manejo de la complejidad y diversidad sociales, surge la necesidad de plantear la interculturalidad como la única alternativa lógica para la integración de todas las personas en la sociedad. Todo ello sobre la base de una nueva noción de identidad que sea capaz de respetar, aceptar e integrar las diferencias conservando además las diversas identidades culturales. En este sentido, el enfoque relacional demuestra ser el único capaz de aportar todo un cuerpo teórico y un nuevo paradigma interpretativo para el análisis y entendimiento de lo que ha supuesto la creciente heterogeneidad de las sociedades modernas y sus repercusiones en el ámbito de la diversidad. Más allá del funcionalismo estructuralista, Donati propone una nueva noción de identidad relacional y el principio de 
LA IDENTIDAD RELACIONAL Y EL PRINCIPIO DE SOLIDARIDAD COMO BASES PARA LA EDUCACIÓN INTERCULTURAL

solidaridad como bases para la interculturalidad en la nueva ciudadanía societaria enormemente compleja y diferenciada que emerge en las sociedades actuales.

Palabras clave: multiculturalismo, modernidad, educación intercultural, identidad relacional, ciudadanía societaria, principio de solidaridad, apertura.

\section{SUMMARY}

Having established the failure of multiculturalism and all theoretical and practical alternatives for the study, analysis and management of social diversity and complexity, emerges the need to raise multiculturalism as the only logical alternative for the integration of all people in the society. All this based on a new sense of identity that is able to respect, accept and integrate the differences, also with preserving the diverse cultural identities. In this sense, the relational approach proves to be the only one capable of providing an entire body of theory and a new interpretive paradigm for analysis and understanding of what it has meant the increasing heterogeneity of modern societies and its implications for diversity. Beyond structuralist functionalism, Donati proposes a new concept of relational identity and the principle of solidarity as a basis for the intercultural in the new societal citizenship highly complex and differentiated that emerges in contemporary societies.

Key words: multiculturalism, modernity, intercultural education, relational identity, societal citizenship, principle of solidarity, openness.

\section{SOMMAIRE}

Ayant constaté l'échec du multiculturalisme ainsi que de toutes ses variantes théoriques et pratiques pour l'étude, l'analyse et la manipulation de la complexité et diversité sociales, surgit le besoin d'envisager l'interculturalité comme unique alternative logique pour l'intégration de toutes les personnes dans la société. Tout ceci sur la base d'une nouvelle notion d'identité en mesure de respecter, accepter et intégrer les différences tout en conservant en outre les diverses identités culturelles. En ce sens, l'approche relationnelle atteste être la seule capable de présenter tout un corpus théorique ainsi qu'un nouveau paradigme interprétatif pour l'analyse et l'entendement de ce qui a supposé l'hétérogénéité croissante des sociétés modernes et leurs répercussions dans le cadre de la diversité. Au delà du fonctionnement structuraliste, Donati propose une nouvelle notion d'identité relationnelle et le principe de solidarité en tant que bases de l'interculturalité chez la nouvelle citoyenneté sociétaire profondément complexe et différenciée qui émerge des sociétés actuelles.

Mots clés: multiculturalisme, modernité, l'éducation interculturelle, identité relationnelle, citoyenneté sociétaire, principe de solidarité, ouverture. 


\section{INTRODUCCIÓN}

El término "cultura" surge en Alemania a finales del siglo XVIII, y aunque existen infinidad de puntos de vista y por lo tanto de definiciones, también existe un consenso en cuanto a la consideración de la cultura como fruto de la sociedad. La cultura es creada por la sociedad y más tarde transmitida mediante un proceso de aprendizaje en el que intervienen varios actores: en primera instancia la familia, complementada por la escuela, grupo de pares, instituciones y grupo social de referencia. Boas $(1938,166)$ ya la definía como "la totalidad de las relaciones y de las actividades intelectuales y físicas que caracterizan el comportamiento de los individuos que componen un grupo social, considerados de manera colectiva y singular en relación con su ambiente natural y otros grupos, con los miembros del mismo grupo y también de todos los individuos respecto a sí mismos".

Por lo tanto, hablar de cultura, sociedad y su evolución supone tener que hablar, ineludiblemente, de educación. La educación puede ser entendida como el resultado de la cultura de cada sociedad, que se transmite y enseña, a su vez, a través de la educación. Al enfrentarnos al binomio cultura-educación, se nos presentan temas como: los derechos culturales, la convivencia y educación en la diversidad cultural, el desarrollo de identidades individuales y culturales y la aceptación de las igualdades y diferencias.

Desde el inicio de los años noventa, los cambios en las relaciones internacionales y la modernización tornada injusta en el plano jurídico, económico y social provocan un alarmante aumento en la falta de igualdad entre el crecimiento económico y las desigualdades sociales. Con todo ello, aparece el llamado fenómeno de la globalización (Altarejos, 2002), concretamente en 1990 cuando se publica el primer informe de Desarrollo Humano impulsado por el Programa de Naciones Unidas para el Desarrollo (PNUD). La globalización económica y sociopolítica borra las fronteras de las naciones y con ello las identidades de las mismas. Conjuntamente aparecen una serie de cambios mundiales influyentes no sólo a nivel económico, sino también político y social, siendo un ejemplo de esto los fenómenos migratorios (Arce Jiménez, 2009), provocando que las culturas arraigadas de cada nación y el propio concepto de cultura como tal comiencen a ser otra vez cuestionados.

Los grupos étnicos y culturales que acoge cada nación poseen su propia cultura, lo cual puede ser algo enriquecedor para la sociedad en su conjunto; pero a la vez suponer un problema si se entiende como requisito el renunciar a la propia cultura para incorporarse a la nueva y así integrarse en la sociedad receptora. Este proceso de asimilación cultural se denomina etnocentrismo (Boas, 1938) y supone el dominio o superioridad de la cultura de los países receptores, mostrándose contrario a cualquier intento de convivencia y respeto hacia la cultura del inmigrante. Suponiendo, además, una oposición radical al principio de solidaridad, que implica el desarrollo de actitudes de corresponsabilidad frente a problemas que deben afectarnos a todos, ya que son de la sociedad. 
LA IDENTIDAD RELACIONAL Y EL PRINCIPIO DE SOLIDARIDAD COMO BASES PARA LA EDUCACIÓN INTERCULTURAL

Quizá la clave del problema de la diversidad cultural resida justo aquí, en la dificultad que representa para los ciudadanos del país que recibe dichos flujos migratorios el reconocer a los mismos como parte de su sociedad, lo que provoca el surgimiento de estados de segregación y marginación (Donati, 1999).

La globalización, así entendida, se traduce en que el concepto de "Aldea Global" (MacLuhan, 1971) nunca ha sido más real, lo que nos ha permitido entender y ser más conscientes del concepto de multiculturalidad. Este fenómeno, como todo fenómeno social -siendo además un concepto nada novedoso debido a que las relaciones o contactos entre los distintos grupos étnicos han estado presentes a lo largo de toda la historia de la humanidad-, afecta a la educación, pudiendo seguir dos caminos, principalmente: la educación monocultural y la educación multicultural. Esta última puede ser traducida como la antesala de la educación intercultural y contiene unos principios y objetivos claros de solidaridad y convivencia, pero manteniendo una visión limitada de lo que significa coexistir con lo diverso aceptando y acogiendo la diferencia como una oportunidad de crecimiento mutuo; tal y como se tratará de poner de manifiesto en este trabajo descriptivo.

En este sentido, el objetivo del presente artículo no es otro que analizar y profundizar en el proceso de evolución que ha tenido lugar a lo largo de la modernidad y la postmodernidad desde el multiculturalismo hasta la interculturalidad como resultado de la enorme diferenciación y creciente complejidad social que desde sus orígenes ha caracterizado a las sociedades industriales modernas. Así como las implicaciones que este proceso evolutivo ha tenido a la hora de adoptar un enfoque teórico u otro en el planteamiento de nuevas intervenciones socioeducativas dirigidas a facilitar la convivencia entre culturas y personas diversas. Para el análisis y estudio de este fenómeno sociológico adoptamos el paradigma relacional propuesto por Pierpaolo Donati, entendiendo que es el único, hasta el momento, que consigue superar el funcionalismo estructural imperante en la modernidad y que ha marcado su impronta en la educación para la convivencia. La teoría relacional analiza la crisis de integración social desde un enfoque relacional tomando como referentes dos nociones que actúan de pilares sustentadores para la propuesta de una ulterior educación para la coexistencia en, con y desde la diversidad: la identidad relacional y el principio de solidaridad.

El presente estudio emplea una metodología analítico-descriptiva y su pretensión es la de clarificar conceptos que creemos fundamentales para abordar el tema de la educación intercultural y así iluminar nuevas formas de intervención socioeducativa. Sin embargo, no es objeto de estudio entresacar, de los elementos analíticos que expondremos, pautas de acción concretas para su conveniente asociación con vías de valiosa reflexión educativa. Tal cuestión podrá ser sin duda objeto de interés ineludible en posteriores trabajos de investigación. 
2. ORIGEN DE LA "MULTICULTURALIDAD" Y SUS IMPLICACIONES EN LA EDUCACIÓN PARA LA CONVIVENCIA

Los conceptos de multiculturalismo y multiculturalidad, aunque usados para referirse a la misma realidad, no indican lo mismo. Como bien distingue el antropólogo Albert Moncusí Ferré (2009), multiculturalismo es un tipo de orientación política cuyo modelo trata de acomodar a la diversidad cultural, reconociéndola explícita y públicamente. La multiculturalidad, por su parte, es la mera presencia de multiplicidad y diversidad cultural en una sociedad. El multiculturalismo es, pues, un fenómeno social y político que tiene su origen en el siglo xx, concretamente en el cúmulo de hechos y movimientos acontecidos en las últimas décadas desde los años sesenta, dando todo ello lugar a una serie de demandas y reivindicaciones educativas. Entre dichos acontecimientos, Sales y García (1997) destacan principalmente los siguientes (1997):

1. Las reivindicaciones sociopolíticas de los años 60: en los Estados Unidos surgió un movimiento reivindicativo para luchar por los derechos civiles. Nacieron de la comunidad negra norteamericana, principalmente, aunque más adelante se les unieron otros grupos étnicos minoritarios, así como mujeres, tercera edad, personas con discapacidades, etc. Defendían el reconocimiento de sus derechos como ciudadanos iguales a los del resto del país, así como de su identidad sociocultural y su legítima participación en las instituciones democráticas norteamericanas. Es decir, se estaba pidiendo una reforma de las instituciones sociales, políticas y educativas, respondiendo esta última con el desarrollo de programas educativos para intentar abordar esa "ideología monocultural y asimilacionista que impedía desarrollar la idea del "pluralismo sociocultural" como fundamento básico democrático" (Sales y García, 1997, 12). Estos movimientos en aras de "la igualdad de oportunidades sociales, políticas, económicas, culturales y educativas" (idem) tuvieron su repercusión en países como Inglaterra, Canadá y Australia, entre otros.

2. El auge del factor étnico: «El concepto de etnicidad se está convirtiendo en uno de los factores de presión sociopolítica más importantes de esta segunda mitad del siglo, junto a los de clase social y género" (idem). Con la modernidad llegó la idea de Estado-nación que pretendía la homogeneización de todos sus miembros, pero los grupos étnicos comenzaron a reivindicar cada vez más el reconocimiento de sus identidades y rasgos culturales para un desarrollo satisfactorio de los mismos.

3. El fenómeno migratorio y la polémica del llamado Tercer Mundo: durante las décadas de los 60 y 70 llega a los países más industrializados (EE. UU., Inglaterra, Australia, Alemania, Francia, Suecia y Suiza) un aumento del flujo migratorio como consecuencia del proceso de descolonización y las desigualdades cada vez mayores entre Norte y Sur, con la superioridad del primero como paraíso de oportunidades. Este gran flujo de inmigrantes 
LA IDENTIDAD RELACIONAL Y EL PRINCIPIO DE SOLIDARIDAD COMO BASES PARA LA EDUCACIÓN INTERCULTURAL

llegó incluso a países como España, Italia y Grecia, habiendo sido ellos mismos, en décadas anteriores, países propiamente emigrantes. Esta heterogeneidad social en las naciones, unida a las malas condiciones de vida de los inmigrantes, causó conflictos en los países receptores, destacando la necesidad de promover cambios sociopolíticos para un mejor afrontamiento de la diversidad cultural, puesto que son los países receptores los responsables de facilitar una serie de estructuras en la sociedad que permitan el desarrollo de una mejor convivencia entre los diversos grupos, sin que ello suponga para ninguno la pérdida de identidad o práctica cultural.

4. La interdependencia mundial: la apertura de las fronteras, la facilidad y rapidez en las comunicaciones y la información y la globalización de los problemas políticos y económicos hacen cada vez más interdependientes a todos los países del mundo, lo que exige, a su vez, mayores y mejores relaciones interculturales. De esta interdependencia surgen también toda una serie de organismos y pactos internacionales en defensa de los Derechos Humanos (Naciones Unidas, 1948), los Derechos Civiles y Políticos (1966) y en contra de las discriminaciones en la enseñanza (unesco, 1980). Todo esto crea el marco apropiado para la defensa de los derechos de todos los ciudadanos y pone de relieve la necesidad de unos valores universales, quedando clara, pues, la gran responsabilidad educativa ante tales cambios mundiales que requieren una respuesta pedagógica adecuada.

El multiculturalismo surge, pues, como una respuesta a cuatro corrientes ideológico-políticas. La primera de ellas es el asimilacionismo (Malgesini y Giménez, 2000; Sales y García, 1997), que impera hasta el momento y se caracteriza por la supremacía de una cultura ante la que los demás pueblos deben renunciar a las suyas propias para adquirir los valores del grupo fuerte. Procura la homogeneidad cultural y la defiende sobre el postulado de que no es posible una convivencia próspera entre personas de distintas culturas. Sin embargo, esta corriente fracasa debido al nuevo reconocimiento del valor de las identidades culturales que surge como consecuencia de los fenómenos migratorios y la interdependencia internacional que emerge en la época.

Hoy hablamos de ciudadanía plural para entender que se puede ser ciudadano en ámbitos territoriales diversos: somos ciudadanos de una ciudad, de una región, de un Estado, de Europa, y ciudadanos del mundo. Una ciudadanía no debe ser absorbida por otra, al contrario, debe extraer el sentido de la otra. Cuando nos trasladamos de un ámbito a otro no debemos perder las otras pertenencias de ciudadanía (Donati, 2003, 220).

A continuación, en los años setenta, se da el paso hacia el integracionismo (Giménez, 1996) con el objetivo de buscar la unión de lo mejor de cada cultura para lograr una cohesión social -"melting pot» (Malgesini y Giménez, 2000)-, pero 
que también fracasó. A partir de ahí surge como tercera corriente el pluralismo (Lamo de Espinosa, 1995), tomando como base la creencia de que todas las culturas son valiosas y viendo positiva la diferencia cultural; aunque esto conlleva el riesgo de caer en un exagerado relativismo cultural. Finalmente, y como nexo de unión entre los extremos del asimilacionismo y el pluralismo, surge en cuarto lugar el interculturalismo (Sales y García, 1997), que habla del diálogo entre culturas para el mutuo enriquecimiento. Es decir, nos plantea una reflexión crítica, empezando por nuestra propia cultura -hasta entonces no hecha-, para lograr una sociedad más justa y solidaria. Es por ello que se considera que el interculturalismo sienta ya las bases de lo que más tarde sería la interculturalidad.

Por aquella época, el liberalismo impregna toda la sociedad y el culturalismo es la teoría sociológica y antropológica que sustenta esta política. "Un número creciente de Estados no sólo toleran las formas de expresión de la diversidad cultural, sino que reconocen en la actualidad que, en lugar de ser trabas molestas, el multiculturalismo y la plurietnicidad son los verdaderos pilares de una integración social democrática" (Stavenhagen, 1996, 276). Sobre dicha base, la multiculturalidad hace referencia únicamente a la diversidad cultural, hecho que queda patente cuando acudimos a su aproximación etimológica, en la que el prefijo "multi" nos indica la existencia de varias culturas juntas pero sin mayor profundización. No va más allá ni supone la relación entre ellas. Ciertamente, se entiende que la multiculturalidad es aquella ideología o modelo de organización social que se traduce en la yuxtaposición de diferentes culturas en un mismo espacio físico, afirmando la posibilidad de vivir armoniosamente sin que ello suponga un intercambio o enriquecimiento. De ahí que inicialmente la multiculturalidad se enfocara como un nuevo fenómeno de fácil manejo, como algo positivo, ya que se veía posible la convivencia de varias culturas mientras cada grupo practicara sus costumbres respetándose mutuamente. Así pues, se puede concluir que el multiculturalismo valora positivamente la diversidad sociocultural y tiene como punto de partida que ningún grupo tiene por qué perder su cultura o identidad propia:

En este modelo, la diversidad existente no desaparece sino que se mantiene, se recrea; no desaparece ni por adquisición de la cultura dominante y abandono del original ni por el surgimiento de una cultura integradora con los aportes de los preexistentes. La diversidad cultural se considera algo bueno y deseable, se fomenta la práctica de tradiciones etnoculturales, se buscan vías para que la gente se entienda e interactúe respetando las diferencias (Argibay, 2003, 302).

Así pues, desde el enfoque de la multiculturalidad se entiende que el pluralismo debe darse, esencialmente, bajo tres premisas (Sales y García, 1997): la aceptación de la diferencia, la defensa del derecho a la diferencia y el reconocimiento de la igualdad de derechos y deberes. Pero, contrariamente a lo que el multiculturalismo pretendía en sus orígenes, la práctica ha puesto de manifiesto que, en realidad, la relación entre dichas culturas es inexistente o en forma de conflicto, siendo 
LA IDENTIDAD RELACIONAL Y EL PRINCIPIO DE SOLIDARIDAD COMO BASES PARA LA EDUCACIÓN INTERCULTURAL

característico de las sociedades multiculturales un clima de indiferencia y tolerancia ante los distintos grupos que la componen. Es decir, se convive en cuanto a que se comparte un mismo espacio-tiempo entre los diversos grupos sociales, pero se vive al mismo tiempo un distanciamiento en cuanto a actitudes, percepciones del otro, reconocimiento, diálogo, etc., evitando así la aceptación y reconocimiento del otro en su dignidad, es decir, como persona; promueve el derecho a la diferencia e igualdad olvidando el derecho a ser reconocido y aceptado, lo que conlleva irremediablemente la negación del otro. Al negar al otro, se niega indirectamente su cultura y por tanto se reconoce como superior y dominante a la otra, negando así el multiculturalismo. Podría argumentarse que esta negación del otro implica de manera indirecta reconocerle. Nada más lejos de la realidad: ese reconocimiento no se hace desde la aceptación, la apertura y la convivencia, sino que conlleva la exclusión de los grupos.

El multiculturalismo está abocado, pues, al fracaso. Fracaso que queda patente en la neutralidad que mantiene ante la reivindicación de los derechos humanos y civiles, cuestión que trata solo a nivel de orden social, en vez de enfocarlo como posibilidad de aumentar y enriquecer los saberes y experiencias (García y Pulido, 1992). Todo ello pone de manifiesto la necesidad de introducir un nuevo enfoque para el estudio, manejo y tratamiento de la diversidad social.

Frente a la multiculturalidad, la interculturalidad supondrá la convivencia entre diferentes culturas, pero también el conocimiento de las mismas, la interrelación y la búsqueda de elementos comunes, lo que dará como consecuencia el enriquecimiento cultural de todos (Casanova, 2005, 190).

Toda esta evolución acaecida durante la modernidad desde el asimilacionismo hasta el multiculturalismo y la consiguiente interculturalidad cobra sentido a la luz del enfoque relacional. Desde la teoría relacional propuesta por el sociólogo Pierpaolo Donati y tomando como referente la noción de identidad y su evolución a lo largo de la modernidad y la postmodernidad, el fenómeno de la multiculturalidad puede ser analizado desde un nuevo enfoque que permite entender el porqué de su aparición y posterior fracaso y la necesidad de dar un paso más allá hacia la interculturalidad.

\section{LA NOCIÓN DE IDENTIDAD SOCIAL DESDE EL ENFOQUE RELACIONAL}

Las sociedades modernas construidas sobre la base de la creación de los Estados de bienestar y siguiendo una lógica de tipo estructural-funcionalista, se caracterizan por una creciente complejidad social fruto de la emergencia de nuevos códigos simbólicos y relacionales que dan lugar a un fenómeno imparable de creciente diferenciación social (Donati, 2011), todo ello como consecuencia de los flujos migratorios y los procesos de industrialización de mediados del siglo xx. Sin embargo, el proceso de integración que llevan a cabo los países occidentales a través de la lógica de inclusión/no inclusión (Donati, 2002, 2004) típicamente 
moderna es de tipo centralista, con un gran énfasis en el papel del Estado como único agente social capaz de conceder el título de ciudadano en la medida en que las personas logran adaptarse a la estructural social y de esta manera pasan a pertenecer al Estado-nación. Esta noción de ciudadanía centralista y homogeneizadora (Stavenhagen, 1996) reconoce al ciudadano en la medida en que se ajusta a una serie de parámetros fijados por el Estado-nación que pretenden eliminar toda diferencia. Con ello se pretende acabar con cualquier amenaza que ponga en peligro la aparente armonía de una sociedad igualitaria, en la que se ignora y rechaza la diversidad y por lo tanto lleva a pensar que todas las personas manifiestan las mismas necesidades (Touriñán, 2009). "El problema de la ciudadanía moderna es que no contempla las diferencias culturales, no quiere conocer la complejidad social, sino que busca la igualdad para todos" (Donati y Colozzi, 1994, 18). En realidad, se intenta esconder la incapacidad del Estado-nación para manejar la creciente heterogeneidad que muestra la ciudadanía moderna.

Por otra parte, el papel centralista y paternalista del Estado da lugar a un neoindividualismo que lleva a los individuos a luchar por su propio bienestar individual, si acaso el de los más allegados; es decir, familiares a su cargo (Izquieta, 2011). Se entiende que, en la medida en que ya es el Estado, en colaboración con el Mercado, el que crea y distribuye bienestar y lo hace llegar a cada individuo a través de la concesión de nuevos derechos y títulos de ciudadanía, cualquier tipo de acción o relación de sacrificio entre individuos carece de todo sentido. Según esta lógica funcionalista de las sociedades modernas, el bien común se entiende como el conjunto de individuos que, trabajando y actuando individualmente, esperan que sea el Estado el que asegure el bienestar social y el buen funcionamiento libre e igualitario de la nación (Donati y Colozzi, 1994). Se erosionan así los flujos de reciprocidad, solidaridad y ayuda mutua existentes en sociedades y épocas anteriores (Izquieta, 2011) y el individualismo imperante lleva al aislamiento de cada individuo en identidades cerradas y autorreferenciales (Taylor, 2002).

Para entender ese cierre autorreferencial que caracteriza al individuo moderno, resulta necesario analizar el concepto de identidad que subyace a este tipo de sociedades. Para ello tomamos como referente la noción de identidad propuesta por el sociólogo Pierpaolo Donati para la teoría relacional. La noción de identidad moderna sobre la que se apoyan las sociedades modernas se rige según la fórmula $A=A$ (Donati, 2006). Esto quiere decir que el ciudadano moderno - ego- solo acepta y reconoce como semejante a aquel que es igual a él y que por lo tanto no manifiesta ninguna diferencia ni rasgo distintivo, sea por raza, origen, cultura, religión, etc. Esto no plantea grandes dificultades en las primeras sociedades modernas, en las que la población, ciertamente, es bastante homogénea y las diferencias son mínimas. Aunque ya entonces, a partir de esa noción de identidad como reconocimiento único del que es igual a ego, se sientan las bases del denominado etnocentrismo (Altarejos, 2002), consecuencia de los códigos 
LA IDENTIDAD RELACIONAL Y EL PRINCIPIO DE SOLIDARIDAD COMO BASES PARA LA EDUCACIÓN INTERCULTURAL

autorreferenciales que impiden la creación de auténticas relaciones con lo externo al propio grupo de referencia (Donati, 1996).

Con la revolución industrial y la creación de los actuales Estados de bienestar, tienen lugar en los países occidentales los grandes flujos migratorios y la consiguiente repentina heterogeneización de las sociedades modernas, que empiezan a crecer en complejidad.

[S]on los movimientos migratorios asociados al fenómeno globalizador los que de una forma más intensa desafían a los presupuestos básicos de la concepción clásica de ciudadanía: la homogeneidad étnica, cultural, religiosa y de nacionalidad en el marco del Estado-Nación. [...] La quiebra de estos presupuestos hace patente que una ciudadanía construida bajo los parámetros de los siglos XIX y XX no responde a los retos de las sociedades multiétnicas, pluriconfesionales, multiculturales y plurinacionales del nuevo milenio (Arce Jiménez, 2009, 21).

Como consecuencia de ello, tiene lugar un proceso de diferenciación sin precedentes que pone de relieve las grandes diferencias sociales inexistentes o latentes hasta el momento, germen de las organizaciones intermedias y asociacionismos y ante los cuales el Estado-nación carece del código simbólico necesario para dialogar con ellos. Suceso que tiene lugar como consecuencia de la lógica funcionalista adoptada en la modernidad, que lleva a reconocer como útil y duradero en el escenario social aquello que demuestra ser eficaz en términos de productividad, rendimiento y eficiencia. Siendo así que todas aquellas acciones, organizaciones y esferas sociales que funcionan empleando otros códigos simbólicos y utilizando otros medios de intercambio que van más allá del enfoque mercantilista son considerados disfuncionales y es por ello que el Estado se muestra incapaz de reconocerlos y mucho menos manejarlos ni darles sentido. Lo que en última instancia provoca esa erosión y eliminación de los flujos de solidaridad, reciprocidad y ayuda mutua a los que ya se ha aludido anteriormente.

Al tiempo que la mundialización se vuelve más tangible para los habitantes del planeta, se impone bruscamente la idea de que "mi vecino acaso no sea ya alguien como yo", descubrimiento que para muchos puede ser traumático, pues pone en tela de juicio las concepciones tradicionales de la vecindad, la comunidad y la relación, hasta entonces inmutables; trastorna modalidades de relación con los demás establecidas desde hace mucho e indica la irrupción de la diversidad étnica en la vida cotidiana (Stavenhagen, 1996, 273).

El Estado-nación, en su pretensión de integración y aceptación del diferente y en aras de la creación de una sociedad pacífica y tolerante, asume la lógica funcionalista de inclusión/no inclusión para la paulatina integración de los individuos en el complejo de ciudadanía nacional. El resultado, sin embargo, es la aparición de nuevas formas de exclusión social (Donati, 1999), producto de la marginalidad de aquellas esferas y tramas relacionales que escapan a la lógica funcionalista adoptada por el Estado. 
Las diferencias sociales siguen existiendo, pero el Estado-nación, incapaz de manejarlas por carecer de un código simbólico idóneo para el diálogo con otras esferas sociales, intenta ignorarlas, mitigarlas o incluso eliminarlas. Al mismo tiempo que establece criterios rígidos y estandarizantes de tipo funcional para la inclusión de los ciudadanos, lo que impide que todos ellos puedan cumplir con dichos parámetros, que por otra parte son transitorios y reversibles: el individuo que hoy es incluido, mañana puede ser excluido y viceversa (Donati y Colozzi, 1994).

Ese afán por conceder nuevos títulos de ciudadanía y alcanzar así una progresiva inclusión -que no integración- de todos los ciudadanos en el Estado-nación, constituye el marco idóneo para la configuración de la denominada multiculturalidad. Concepto que tiene su origen, nuevamente, en una noción de identidad propia de las sociedades postmodernas enormemente complejas que, de alguna manera, necesitan hallar la fórmula para manejar la creciente diferenciación social e incluir al extranjero o inmigrante en la estructura social homogénea y cerrada. Así pues, la identidad moderna a la que se aludía anteriormente da paso en este nuevo escenario social crecientemente complejo y diverso a la identidad postmoderna, que se identifica con la fórmula $A=$ no (no $A$ ). Según esta fórmula, la persona se identifica en contraposición al diferente y por lo tanto en negación a él. Esto se traduce como el intento que hace el ciudadano (y por ende el Estado-nación) - ego- de aceptar al extranjero o inmigrante -alter-, a partir del cual solo reconoce e identifica las diferencias y por lo tanto aquellos rasgos que lo hacen distinto a él y que finalmente constituyen motivo de alejamiento y negación (Donati, 2006). En definitiva, falta de aceptación y reconocimiento de altery por lo tanto impedimento para la apertura y la consiguiente acogida de la diversidad.

Así, la sociedad postmoderna aboga por la aceptación e inclusión del extranjero y pretende crear una nueva ciudadanía de tipo multicultural en la que las diferentes culturas, etnias y razas convivan en un clima de paz y armonía basado en el respeto mutuo y la tolerancia (Naval y Altarejos, 2000) -entendida esta como aceptación de un mal (la inmigración) por un bien mayor (la paz social)-. "Hay otra noción que es hoy objeto de múltiples debates, particularmente en los países en transición: la de la tolerancia. Quizá en los años venideros no sea suficiente con la tolerancia y para vivir juntos haya que pasar de la tolerancia a una cooperación activa. Esta implica esfuerzos comunes para proteger la diversidad. Ya no habrá que decir "yo soy tolerante", sino "yo respeto" (Kornhauser, 1996, 261).

El espíritu democrático no podría contentarse, empero, con una forma de tolerancia minimalista que consistiera únicamente en avenirse a la alteridad. Esa actitud que pretende ser simplemente neutra está a merced de las circunstancias, que pueden invalidarla cuando la coyuntura económica o sociológica vuelve especialmente conflictiva la cohabitación de varias culturas. Por consiguiente, conviene superar la simple noción de tolerancia y basar la enseñanza del pluralismo en el respeto y el aprecio de las otras culturas (Delors, 1996, 64). 
LA IDENTIDAD RELACIONAL Y EL PRINCIPIO DE SOLIDARIDAD COMO BASES PARA LA EDUCACIÓN INTERCULTURAL

La realidad es que la sociedad postmoderna acepta la entrada y permanencia de inmigrantes extranjeros siempre siguiendo una lógica funcionalista, según el interés productivo que puedan aportar y su capacidad de adaptación a las estructuras existentes. Así pues, tolera que convivan con los ciudadanos pertenecientes al Estadonación pero manteniendo y resaltando siempre las diferencias, que constituyen la base sobre la que los ciudadanos forjan su propia identidad nacional y cultural y por lo tanto mantiene una distancia constante entre unos y otros, siempre en relación de enfrentamiento y conflicto latentes. Esto impide la verdadera aceptación y reconocimiento del otro -alter-como igual a mí-ego-, en tanto que persona y ser único con dignidad (Spaemann, 2000), al mismo tiempo que manifiesta diferencias que deben ser aceptadas e integradas, que no eliminadas, para alcanzar la verdadera coexistencia entre culturas diversas (Donati, 2006).

Pero, corroborada la crisis del multiculturalismo y la multiculturalidad y ante la necesidad de idear nuevas formas y cauces de verdadera integración de los inmigrantes y extranjeros en las sociedades occidentales, se requiere por tanto un cambio en la noción de identidad. Cambio que hasta ahora ninguna teoría sociológica ha sabido ver de forma nítida en ese sentido evolutivo del que hablábamos en la introducción. Es necesaria una nueva identidad social que sea capaz de aceptar y acoger verdaderamente al diferente estableciendo una relación en la que se acepten e integren las diferencias y al mismo tiempo sea capaz de reconocer lo que de común hay a todos los hombres por encima de toda diferencia: la condición humana y la dignidad personal (Spaemann, 2000).

En este sentido, la sociología relacional de Pierpaolo Donati constituye un nuevo paradigma para el estudio y análisis del cambio social en términos de complejidad que aporta una nueva luz en torno a la cuestión de la identidad social y cultural y el manejo de la diversidad para alcanzar la verdadera coexistencia. Siguiendo la teoría relacional y la evolución en la noción de identidad, Donati (2006) propone la identidad relacional como el paso lógico y necesario para la creación de relaciones de aceptación y acogida entre todos los hombres en aras de la verdadera integración social en una sociedad diversa y compleja. Noción que aquí utilizamos para fundamentar y explicar la aparición de la interculturalidad como el paso evolutivo a partir de la patente crisis del multiculturalismo. Esta noción de identidad relacional, junto con el principio de solidaridad en el que más adelante ahondaremos, constituyen el fundamento ineludible de toda estrategia e intervención socioeducativa que ponga su foco de atención en la interculturalidad como oportunidad de crecimiento y perfeccionamiento mutuos (Vila, 2005).

\section{LA IDENTIDAD RELACIONAL: UNA OPORTUNIDAD PARA LA INTERCULTURALIDAD}

Con la crisis de los Estados de bienestar se pone de manifiesto la verdadera crisis de la noción de integración y ciudadanía empleadas por las sociedades modernas (Donati, 1984), que se han visto incapaces de manejar la creciente complejidad social propia de los países industrializados. Así lo corrobora Donati (1999, 36) 
al afirmar que "la idea que se debe tener bien presente es que la actual crisis de integración política comporta la crisis de una cierta idea (moderna) de democracia, y ambas se expresan en la crisis de la correspondiente forma de ciudadanía".

En esta nueva etapa, emerge en la denominada sociedad dopo-moderna (Donati, 2003, 161) una nueva ciudadanía societaria de tipo asociativo que, sobre el principio de solidaridad, aboga por la aceptación, reconocimiento e integración de las diferencias patentes de los sujetos sociales -individuales o colectivos- en nuevas esferas de pertenencia (Herrera y Castón, 2003) cuyo funcionamiento autónomo se sustente en códigos simbólicos propios. Estas esferas o comunidades intermedias propias del Tercer Sector (Izquieta, 2011) o "privado social" (Donati, 2011, 157), y que median entre el Estado-nación y el individuo, se crean sobre la base de una nueva noción de identidad dopo-moderna de tipo relacional que emplea la fórmula $A=r(A$, no $A)$ (Donati, 2006). Decir que

la expresión "dopo-moderno" indica literalmente lo que viene después de la modernidad, en el sentido de que no se organiza según valores, principios y normas típicamente modernos, sino de otro tipo. La expresión no debe confundirse con postmoderno, que indica un tipo de organización social que corresponde a la cultura designada con tal término (generalmente llamada de pensamiento débil, fragmentaria, esteticista, caótica y con racionalidad limitada) (Donati, 2003, 161).

La identidad entendida como relación supone la puesta en relación de ego y alter que, aceptando y reconociendo las diferencias de cada quien, son, además, capaces de identificar aquello que de común hay a ambos, que es la condición humana y que en última instancia permite reconocer la dignidad de cada quien por ser quien es, único en su ser personal (Bernal, Rodríguez, Altarejos y Naval, 2005). La identidad relacional permite, así, no solo no eliminar las diferencias en aras de la homogeneización, sino que además les da visibilidad y las erige como seña de identidad de nuevos sujetos sociales colectivos (Donati y Colozzi, 1994). El objetivo, en este caso, no es crear grupos sociales aislados y autorreferenciales que solamente conviven unos frente a otros en sentido de negación, aunque tolerando la presencia mutua, como resulta con la multiculturalidad; sino poner dichas diferencias en relación, con el fin de generar un «intercambio de dones diversos, equivalentemente simbólicos, para la creación de un bien que, por ser relacional, puede ser producido y disfrutado sólo conjuntamente" (Donati, 2004, 160).

Lo que se consigue al poner en relación a ego y alteres facilitar el reconocimiento mutuo a partir de lo que de común hay a ellos (Altarejos, 2002) y así favorecer la verdadera apertura al otro como diferente y al mismo tiempo igual a mí. De esta manera, se logra establecer verdaderas relaciones interpersonales que hacen referencia al otro, al diferente (refero), al tiempo que se genera un vínculo (religo) entre ego y alter (Donati, 1999), y no meras interacciones personales movidas por el interés individual. Todo ello da lugar a una realidad sui generis que los excede a ambos y que es capaz de reconocer y aceptar las diferencias integrándolas en una misma identidad colectiva que une a las personas en relación y que además 
LA IDENTIDAD RELACIONAL Y EL PRINCIPIO DE SOLIDARIDAD COMO BASES PARA LA EDUCACIÓN INTERCULTURAL

las compromete en torno a objetivos y fines comunes. Es por ello que esa relación constituye un bien relacional, en la medida en que, al acoger a alter-el inmigrante o extranjero- y reconocerle en su ser personal, ego-el ciudadano nacional- valora las diferencias como una oportunidad de apertura y conocimiento de la diversidad que le enriquece y que, por tanto, contribuye a su propio crecimiento personal. La relación es, por tanto, un bien compartido del que ambos disfrutan y que nunca se agota mientras dicha relación siga existiendo (Donati, 2007, 181).

Por otra parte, es importante asumir la diversidad y la pertenencia múltiple como riqueza. La enseñanza del pluralismo no sólo es una protección contra las violencias, sino además un principio activo de enriquecimiento cultural y cívico de las sociedades contemporáneas. Entre el universalismo abstracto y reductor y el relativismo para el cual no hay exigencia superior más allá del horizonte de cada cultura particular, conviene afirmar a la vez el derecho a la diferencia y la apertura a lo universal (Delors, 1996, 62).

Así pues, solo la identidad entendida como relación, tal y como lo plantea la teoría relacional, permite y da pie a la creación de auténticas relaciones de apertura al otro y sobre esa base recuperar los flujos de reciprocidad, solidaridad y ayuda mutua que vuelven a emerger en la ciudadanía societaria en torno a las identidades colectivas de tipo asociativo (Donati, 1999). Recuperada esa reciprocidad "que se basa en el código simbólico de la mutua solidaridad y que emplea medios como la confianza y el darse recíproco" (Donati y Lucas, 1987, 67) y que por lo tanto acepta, reconoce y acoge, se puede hablar entonces de los derechos y deberes que todos los ciudadanos, por ser personas y no solo individuos funcionales, deben asumir como responsabilidad directa y personal en aras del verdadero bien común. Todo ello posible a través de la descentralización del Estado-nación de tipo asistencialista (Donati, 1997) y el reconocimiento del resto de agentes sociales como creadores y distribuidores de bienestar, y por lo tanto responsables también de las diferencias existentes en la sociedad. Surge así el principio de solidaridad (Donati, 1999) que sirve de base y fundamento de la interculturalidad, entendida no sólo como relación de respeto y tolerancia, sino también de reconocimiento y acogida y consiguientemente como oportunidad para la reciprocidad, el intercambio y la ayuda mutua entre personas.

Esta referencia intrínseca a los otros en cuanto que personas se formula como solidaridad, que es así mucho más que una actitud benéfica, y por lo mismo ocasional, y en definitiva, precaria (Altarejos, 2006, 148).

A la vista de todo lo dicho anteriormente, sólo sobre la base de la identidad social entendida como relación entre ego y alter -y no como eliminación (identidad moderna) o negación o contraposición a él (identidad postmoderna) - y tomando como base la lógica de diferenciación/integración propia del código relacional y el principio de solidaridad y ayuda mutua (Donati, 2002), se fundamenta la necesidad de dar un paso más allá respecto de la educación multicultural y comenzar a 
hablar de la denominada interculturalidad, entendida como una oportunidad para la verdadera apertura a las diversas culturas y la coexistencia (Naval y Altarejos, 2002) basada en el reconocimiento y la integración de la diversidad y las consiguientes necesidades de los nuevos sujetos sociales. "En este sentido, en importante promover una educación intercultural que sea realmente un factor de cohesión y de paz" (Delors, 1996, 60).

A través de estos procesos de diferenciación podría nacer una nueva cultura de "hacer sociedad", según un código simbólico y normativo de tipo relacional. La ausencia de procesos degenerativos no está nunca garantizada, pero el código relacional podría, en principio, en cuanto código de reciprocidad, prevenir los conflictos y patologías mejor de lo que puede hacerlo el código de inclusión (Donati, 2002, 54).

Dicho esto, se pone de manifiesto que el enfoque relacional aporta todo un cuerpo teórico capaz de analizar desde la noción de identidad y el principio de solidaridad cómo, tanto el multiculturalismo como la interculturalidad y el resto de corrientes emergentes durante la modernidad, no han sido sino diferentes manifestaciones de las diversas maneras de entender la ciudadanía, la integración social y la relación con el otro, con el extranjero o inmigrante. Son esas formas de relación o de no relación, precisamente, las que han dado lugar a nuevos cambios sociopolíticos que a lo largo de la modernidad y con posterioridad a ella han pretendido hacer frente a los crecientes flujos migratorios y sus consecuencias en cuanto a heterogeneidad social, crecimiento de la diversidad y la consiguiente convivencia entre culturas e identidades distintas.

Así demuestra la teoría relacional que, sólo desde la asunción de una noción de identidad entendida como relación y sobre la base del principio de solidaridad con origen en la propia relación de reciprocidad y la consiguiente apertura al otro, cobra sentido y fundamento el plantear la interculturalidad como un paso evolutivo que va más allá del mero multiculturalismo para el estudio y manejo de la diversidad social en esta aldea global.

\section{LA EVOLUCIÓN HACIA LA "INTERCULTURALIDAD"}

Una vez analizada la evolución que ha experimentado el multiculturalismo desde la aparición de los primeros flujos migratorios en las sociedades modernas y su fundamento sociológico desde la teoría relacional propuesta por Donati a partir de la noción de identidad, toca analizar ahora los orígenes y desarrollo de la denominada interculturalidad. Siempre entendida como un paso evolutivo lógico una vez constatado el fracaso del multiculturalismo para el estudio, análisis y manejo de la diversidad social.

Pluricultural es la sociedad compuesta por un crisol de culturas sin la existencia de una convivencia como tal. El término transcultural implica la aceptación del otro traducida en una relación más intensa. Resultado de esa relación surgen unos 
LA IDENTIDAD RELACIONAL Y EL PRINCIPIO DE SOLIDARIDAD COMO BASES PARA LA EDUCACIÓN INTERCULTURAL

hechos culturales nuevos entendidos no como la unión de culturas sino como la fusión nacida de la verdadera convivencia y respeto, llevando esto a la conciencia de la necesidad de unos valores universales.

La aparición del término interculturalidad surge como respuesta a las carencias que presentaban la multiculturalidad y el multiculturalismo. Su inicio se sitúa en la Francia de los años setenta como consecuencia de la necesidad existente en el país de atender a los inmigrantes (Bernal, 2003).

Su prefijo "inter" originario del latín, significa "entre, en medio". Inicialmente, puede entenderse que este concepto hace referencia a lo existente entre culturas debido a la acción de ambas. Ciertamente, hablar de interculturalidad supone hablar de respeto, reconocimiento, comprensión, comunicación, aceptación de valores y culturas, apertura, interacción e intercambio; es decir, un sinfín de riquezas derivadas de la verdadera relación entre culturas. Todo ello se traduce y conlleva la reivindicación de la necesidad de unos derechos y deberes compartidos, del derecho a la diferencia cultural, sin significar en ningún momento la pérdida de la propia cultura. Luego interculturalidad significa ampliar nuestra visión del mundo, nuestros puntos de vista. Debemos salir de la postura eurocentrista que nos caracteriza para pasar a otras mucho más enriquecedoras (Clifford, 1995).

Con el multiculturalismo "no hay diferenciación porque haya diferencias, sino que se dan las diferencias porque hay diferenciación" (García Amilburu, 2008, 87); en cambio, con la interculturalidad "se trataría por tanto de recuperar un modo de ser del ciudadano en el que quepan las diferencias en una sociedad pluralista e intercultural, dentro del marco que nos ofrece la globalización" (Naval, 2003, 426).

En definitiva, la interculturalidad se promueve como una propuesta de organización sociopolítica que fomenta las relaciones entre esa sociedad diversa y que además posee una dimensión ética consistente en el esfuerzo por la igualdad con un respeto por la diferencia (Bernal, 2003).

La diferencia esencial entre el multiculturalismo y el interculturalismo es el compromiso que precisa y reclama este último concepto (Taylor, 2012). Compromiso que exige la corresponsabilidad de todos los grupos que compongan la sociedad, enfocada a lograr una relación tal que otorgue paz, cohesión y participación. Esto no conlleva perder la propia identidad, es decir, se trata de adoptar una actitud de apertura y respeto hacia el otro, que logre una verdadera convivencia que consista no sólo en compartir un espacio y un tiempo, sino también vida, formando y facilitando puntos de encuentro y relación que den lugar a hechos comunes fruto de la fusión de ambas culturas. Debemos tener en mente que lo esencial no es tanto la cultura sino los otros. El diálogo será un factor decisivo e imprescindible en esta tarea de respeto a las demás culturas, vivencia de la propia cultura y creación de una nueva, fruto de la síntesis cultural. Esta armonía es realmente difícil de alcanzar, pero si vamos a lo más profundo de las personas, vemos que, pese a la cultura de cada una, todas poseemos aspectos en común. Estos pueden ser 
objetivos, proyectos de vida, búsqueda de la felicidad, etc., pero lo más esencial e ineludible que nos une es la dignidad humana.

Ante estos cambios en las sociedades y su orden sociopolítico, la educación siempre es responsable de adaptarse a ellos para dar una respuesta. Es indiscutible la capacidad y, por lo tanto, la responsabilidad que poseen los sistemas educativos de cada país en la formación de los ciudadanos para la aceptación y adaptación a los distintos cambios sociales (Soriano, 2007).

La educación puede ser un factor de cohesión si procura tener en cuenta la diversidad de los individuos y de los grupos humanos y al mismo tiempo evita ser a su vez un factor de exclusión social. El respeto de la diversidad y de la especificidad de los individuos constituye, en efecto, un principio fundamental, que debe llevar a proscribir toda forma de enseñanza normalizada (Delors, 1996, 59).

Queda claro que, de la calidad de la educación de cada cultura, dependerá el futuro de dicha sociedad; y un pueblo educado es un pueblo libre. Los sistemas políticos facilitan, promueven, pero es la educación la que a través de sus programas llega finalmente a cada persona y debe ser la encargada de intentar lograr el desarrollo de unas actitudes de respeto y aceptación básicas para el reconocimiento del otro y el logro de una convivencia pacífica y enriquecedora. La educación es el medio para transmitir la cultura de un país, por lo que si dicho país posee una diversidad de ciudadanos y grupos étnicos, a esa primera tarea se le suma el interés por fomentar la comprensión e interacción de sus educandos. En el ámbito educativo, el pluralismo cultural no debe considerarse un aspecto negativo, sino una fuente de riquezas para todos los que lo conforman. La educación en la diversidad será, por tanto, una tarea obligada a llevar a cabo hoy en día, dada la realidad de diversidad cultural en la que nos encontramos (Lalueza y Crespo, 2012). La educación intercultural queda englobada dentro de la Educación para el Desarrollo, definida como:

La Educación para el Desarrollo se basa en un conjunto de propuestas teóricas y prácticas destinadas a transformar el conocimiento, las percepciones, las actitudes de la población de los países enriquecidos para lograr una mejora de las relaciones Norte-Sur en la línea de las propuestas del Desarrollo Humano. Su filosofía y su praxis consisten en concienciar a personas, colectivos e instituciones sobre la realidad Norte-Sur y ofrecer las vías de participación responsable en dichos procesos de solidaridad. Trata de modificar la situación reflejada por el diagnóstico social que indica que la mayoría de los y las habitantes de las sociedades "desarrolladas" ignora las interdependencias Norte-Sur, y no comprende las funciones de la cooperación internacional (Argibay y Celorio, 2005, 11).

Luego, en el fondo, la educación intercultural busca concienciar a las sociedades y lograr con ello un cambio de actitudes que nos haga darnos cuenta de la realidad en la que vivimos y de la responsabilidad que todos poseemos en el logro de una verdadera convivencia. Pero dicho objetivo no se cubre únicamente informando 
LA IDENTIDAD RELACIONAL Y EL PRINCIPIO DE SOLIDARIDAD COMO BASES PARA LA EDUCACIÓN INTERCULTURAL

bien a los ciudadanos, sino que hay que formar, y en todas las dimensiones de la persona (Soriano, 2007).

La convivencia con los otros no se facilita sólo por un conocimiento mutuo. Los prejuicios van más allá de los estereotipos, no se evitan únicamente por un conocimiento de calidad; lo afectivo y sobre ello lo volitivo entran en juego. El asunto candente es entender y aceptar que hay que repartir bienes y compartir valores con personas que pueden suscitar la existencia de manera diferente, lo que a todos plantea cambiar en algún aspecto la forma de vivir. Ante lo nuevo se sospecha siempre un riesgo a perder algo. La educación intercultural no es cuestión de la escuela sino que ha de sobreponerse en el seno de todos los ámbitos sociales (Bernal, 2003, 98-99).

\section{IMPLICACIONES DEL ENFOQUE RELACIONAL EN LA EDUCACIÓN INTERCULTURAL}

Como conclusión a todo lo analizado hasta ahora, queda patente que la educación intercultural en el siglo XxI cobra sentido en la medida en que se sustenta en la verdadera apertura al otro tomando siempre como referente a la persona en su ser único y personal y su dignidad humana (Stavenhagen, 1996). Para ello resulta necesario tomar como fundamento una noción de identidad de tipo relacional capaz de aceptar, reconocer y acoger al diferente por ser quien es -persona humana igual a mí- y no por lo que es -extranjero, inmigrante, de otra raza, cultura, religión y en definitiva diferente a mí (Spaemann, 2000)-. Que por lo tanto permita y promueva la apertura a los demás más allá de los grupos e identidades autorreferenciales.

Sobre esa relación de apertura y acogida cobran sentido las acciones e iniciativas solidarias de reciprocidad, intercambio y ayuda mutua como forma de responsabilización personal y social para con los más necesitados y como respuesta a las diferencias e injusticias sociales. Acciones, por tanto, que vayan más allá del emotivismo y el sentimentalismo que frecuentemente caracterizan a aquellas iniciativas de sensibilización y acción social que, por reducirse a nociones de tolerancia, aceptación y convivencia con el diferente, consiguen movilizar a las personas en un momento o ante un hecho puntual, pero que no terminan de producir cambios en la conciencia de cada quien. Esa falta de conciencia social impide suscitar en ellos un verdadero compromiso cívico con la transformación social, entendido como la obligación de todos en tanto que ciudadanos para con las necesidades de las personas y la mejora de la sociedad. Y el peligro que subyace a estas acciones aparentemente solidarias, como ya se ha explicado anteriormente citando a Delors, es que, no habiendo entendido verdaderamente lo que significa la acogida y la apertura a la diversidad y por lo tanto a las necesidades y derechos de las personas, dependen de la coyuntura político-económica. Esta dependencia coyuntural y la precariedad económica, social y cultural que hoy es tan patente en las sociedades actuales hacen tambalear ante cualquier cambio social la aparente 
armonía y la ficticia cohesión social, sustentadas sobre la falsa aceptación del que es diferente.

Concluimos, por tanto, que el enfoque relacional con su lógica de diferenciación/integración y el principio de solidaridad que postula a partir de la identidad relacional demuestra ser un nuevo paradigma sociológico que aporta la fundamentación teórica necesaria para sustentar nuevas prácticas en el terreno de la educación intercultural (Escarbajal, 2011) y la educación en, con y desde la diversidad.

Queda además, patente, que la ciudadanía pasa en la actualidad de ser de tipo adscriptiva, cuyo reconocimiento viene dado por la concesión de nuevos derechos y el sometimiento del individuo al Estado-nación (Donati, Maccarini y Stanzani, 1997, 202), a ser progresivamente más adquirida. "La ciudadanía es un hábito que debe adquirirse y desarrollarse" (Naval, 2003, 433) y, por lo tanto, la educación debe contemplar entre sus objetivos el desarrollo en las personas de una serie de conocimientos, hábitos, valores y conductas que les lleven a aceptar y reconocer a los demás, comprometerse conjuntamente en torno a objetivos y metas comunes y asumir como propios nuevos deberes y responsabilidades frente a las injusticias de esta sociedad enormemente compleja y diversa. El objetivo, en definitiva, es formar y educar personas que, además de ser ciudadanos competentes, productivos y eficaces, sean al mismo tiempo personas implicadas y activamente comprometidas con la creación y distribución de auténtico bienestar humano y además responsables como parte implicada en la aparición de nuevos problemas sociales en el seno de una ciudadanía enormemente diferenciada y en la consolidación de verdadero tejido social (Puig, Domene y Morales, 2010).

La ciudadanía, entonces, puesto que se considera un hábito, debe ejercitarse y ponerse en práctica y para ello es necesario que el Estado promueva y cree nuevos cauces a través de los cuales las personas puedan verdaderamente ejercer su ciudadanía, adoptando un rol activo y participativo, implicándose en los problemas sociales y en la atención y cuidado de las personas a través de relaciones personales y verdaderamente humanas.

Confrontada a la crisis del vínculo social, la educación debe asumir la difícil tarea de transformar la diversidad en un factor positivo de entendimiento mutuo entre los individuos y los grupos humanos. Su más alta ambición es brindar a cada cual los medios de una ciudadanía consciente y activa, cuya plena realización solo puede lograrse en el contexto de sociedades democráticas (Delors, 1996, 56).

Con todo ello, la nueva educación intercultural para el siglo xxi debe formar y capacitar a las personas para, una vez reconocidas y apreciadas las diferencias, ser capaces de abrirse a esa diversidad y llegar a crear auténticas relaciones humanas basadas en el respeto y reconocimiento mutuo conservando y valorando siempre la propia identidad personal y cultural y la de los demás. Relaciones que en sí mismas constituyen bienes para todos los que las comparten y que abren un nuevo cauce para la interculturalidad sobre el principio de solidaridad y ayuda mutua. 
LA IDENTIDAD RELACIONAL Y EL PRINCIPIO DE SOLIDARIDAD COMO BASES PARA LA EDUCACIÓN INTERCULTURAL

La educación debe seguir dos orientaciones: el descubrimiento del otro (conocerse a uno mismo, y observar y aceptar las diferencias entre los demás) y participar en proyectos comunes (Naval, Lara, Ugarte y Sádaba, 2010, 40).

En la práctica educativa, esto supondría la recuperación de los dos pilares a los que Delors aludía a la hora de fijar los objetivos para la educación en el siglo XXI: "Aprender a vivir juntos" $\mathrm{y}$ "Aprender a ser".

Parecería entonces adecuado dar a la educación dos orientaciones complementarias. En el primer nivel, el descubrimiento gradual del otro. En el segundo, y durante toda la vida, la participación en proyectos comunes, un método quizá eficaz para evitar o resolver los conflictos latentes. La educación tiene una doble misión: enseñar la diversidad de la especie humana y contribuir a una toma de conciencia de las semejanzas y la interdependencia entre todos los seres humanos (Delors, 1996, 104).

Así pues, y en vista de lo expuesto en este artículo, se considera de sumo interés que ulteriores estudios pongan su foco de atención en la manera de idear y diseñar nuevas estrategias de intervención socioeducativa que, asumiendo la teoría relacional como nuevo paradigma sociológico de potenciales aportaciones para el ámbito educativo y tomando como referente las dos nociones de identidad relacional y principio de solidaridad por él propuestos, lleven a la reformulación de lo que actualmente significa educar para la coexistencia en, con y desde la diversidad. Revalorizando para ello el papel que la sociedad civil puede y debe jugar como agente educativo (Touriñán, 2009) que actúa en colaboración con la escuela, la familia y el Estado y plasmando lo que la teoría relacional propone en este sentido, en competencias, destrezas y actitudes concretas que formen y eduquen a la persona favoreciendo su apertura a los demás, suscitando su encuentro con el otro y potenciando la aceptación y el reconocimiento de la diversidad como una oportunidad de relación personal, perfeccionamiento recíproco y crecimiento mutuo.

\section{REFERENCIAS BIBLIOGRÁFICAS}

Altarejos, F. (2002) El problema de la identidad en la praxis social: afiliación y filiación. Studia Poliana, 4, 61-80.

- (2006) La co-existencia, fundamento antropológico de la solidaridad (K. Wojtyla, R. Spaemann, L. Polo). Studia Poliana, 8, 119-150.

ARCE JimÉnez, C. (2009) La ciudadanía en la era de la globalización: el reto de la inclusión. Madrid, Editorial Universitaria Ramón Areces-Fundación Aequitas.

ARgibay, M. (2003) Educación para el desarrollo en un mundo globalizado. Revista Española de Educación Comparada, 9, 301-308.

Argibay, M. y Celorio, G. (2005) La educación para el desarrollo. Vitoria, Servicio Central de Publicaciones del Gobierno Vasco. 
LA IDENTIDAD RELACIONAL Y EL PRINCIPIO DE SOLIDARIDAD COMO BASES PARA LA EDUCACIÓN INTERCULTURAL

BERNAL, A. (2003) La educación entre la multiculturalidad y la interculturalidad. ESE: Estudios sobre Educación, 4, 85-101.

Bernal, A.; Rodríguez, A.; Altarejos, F. y Naval, C. (2005) La familia como ámbito educativo. Pamplona, Rialp.

BOAs, F. (1938) Cuestiones fundamentales de antropología cultural. Buenos Aires, Solar.

Bueno, G. (2002) Etnocentrismo cultural, relativismo cultural y pluralismo cultural. Revista Crítica del Presente: El Catoblepas, 2.

Casanova, J. (2005) Atención a la diversidad y formación del futuro maestro. Revista de Ciencias de la Educación, 21, 185-196.

Clifford, J. (1995) Dilemas de la cultura. Barcelona, Gedisa.

Delors, J. (1996) La educación encierra un tesoro. Madrid, Santillana-Ediciones UNESCO.

Donati, P. (1984) Risposte alla crisi dello stato sociale. Le nuove politiche social in prospettiva sociologica. Milano, Franco Angeli.

- (1996) Teoria relazionale della società. Milano, Franco Angeli.

- (1997) L'Etica civile alla fine del XX secolo: tre scenari. Milano, Mondadori.

- (1999) La ciudadanía societaria. Granada, Editorial Universidad de Granada.

- (2002) Ciudadanía y sociedad civil: dos paradigmas (ciudadanía lib/lab y ciudadanía societaria). Reis, 98, 37-64.

- (2003) Manual de sociología de la familia. Barañain, EUNSA.

- (2004) Nuevas políticas sociales y Estado social relacional. Reis, 108, 9-47.

- (2006) Repensar la sociedad. Madrid, Ediciones Internacionales Universitarias.

- (2007) Capitale sociale, reti associazionali e beni relazionali, en SCALvini, F. (ed.) Impresa sociale. Trento, ISSAN Edizioni, 166-189.

- (2011) Relational sociology: a new paradigm for the social sciences. London, Routledge.

Donati, P. y Colozzi, I. (eds.) (1994) La cultura della cittadinanza oltre lo Stato assistenziale. Roma, Edizioni Lavoro.

Donati, P. y Lucas, A. (1987) La política social en el Estado de Bienestar: el desafío de los sistemas complejos. Reis, 37, 57-68.

DONATI, P.; MACCARINI, A. M. y STANZANI, S. (1997) L'asociazionismo sociale oltre il welfare state: quale regolazione? Milano, Franco Angeli.

Escarbajal, A. (2011) Hacia la Educación Intercultural. Pedagogía Social. Revista Interuniversitaria, 18, 131-149.

GarCía Amilburu, M. (2008) Etnocentrismo, relativismo cultural y pluralismo. Multiculturalismo, identidad cultural y globalización, en BOuchè PERIS, H. y cols. (eds.) Antropología de la educación. Madrid, Síntesis, 97-112.

García Castaño, F. J. y Pulido Moyano, R. (1992) Educación multicultural y antropología de la educación, en Fermoso, P. (ed.) Educación intercultural. La Europa sin fronteras. Madrid, Nancea, 35-70.

GiménEZ, C. (1996) La integración de los inmigrantes y la interculturalidad. Arbor. Ciencia, Pensamiento y Cultura, 607, 119-49.

Herrera, M. y Castón, P. (2003) Las políticas sociales en las sociedades complejas. Barcelona, Ariel.

IzQuieta Etulain, J. L. (2011) Voluntariado y Tercer Sector. Cultura, participación cívica y organizaciones solidarias. Madrid, Editorial Tecnos.

Kornhauser, A. (1996) Suscitar la ocasión, en Delors, J. (ed.) La educación encierra un tesoro. Madrid, Santillana-Ediciones UNESCO, 257-264. 
LA IDENTIDAD RELACIONAL Y EL PRINCIPIO DE SOLIDARIDAD COMO BASES PARA LA EDUCACIÓN INTERCULTURAL

Lalueza, J. L. y Crespo, I. (2012) Dossier: Diversidad cultural, investigación psicológica e intervención educativa. Cultura y Educación, 24 (2), 131-135.

LAMO DE EsPinosa, E. (ed.) (1995) Culturas, estados, ciudadanos. Una aproximación al multiculturalismo en Europa. Madrid, Editorial Alianza.

Macluhan, M. (1971) Guerra y Paz en la Aldea Global. Barcelona, Martínez Roca.

Malgesini, G. y GiméneZ, C. (2000) Guía de conceptos sobre migraciones, racismo e interculturalidad. Madrid, Catarata.

Moncusí FerRé, A. (2009) Imaginar el espacio urbano desde la alteridad: convivencia intercultural y mediación ciudadana en un barrio de Valencia, en BlanCO, C. y BARBERO, I. (eds.) Pautas de asentamiento de la población inmigrante: implicaciones y retos sociojurídicos. Madrid, Dykinson, 355-378.

Muñoz Sedano, A. (2002) Hacia una educación intercultural: enfoques y modelos, en DeL Canto, A. C.; Cleminson, R.; Gordo López, A. J. y Muñoz Sedano, A. (coords.) La educación intercultural. Madrid, Consejería de Educación, Comunidad de Madrid, 43-53.

Naval, C. (coord.) (2003) Respuestas del grupo de investigación en educación para la ciudadanía (GIEC) de la Universidad de Navarra. Revista de Educación, número extraordinario, 425-442.

Naval, C. y Altarejos, F. (2000) Filosofía de la educación. Barañain, eunsa.

NAval, C.; LARA, S.; UGARTE, C. y SÁDABA, Ch. (eds.) (2010) Educar para la comunicación y la cooperación social. Pamplona, Consejo Audiovisual de Navarra.

Petrella, R. (2005) El derecho a soñar: propuestas para una sociedad más humana. Barcelona, Intermón Oxfam.

Puig Gutiérrez, M.; Domene Martos, S. y Morales lozano, J. A. (2010) Educación para la ciudadanía: referentes europeos. Teoría de la Educación, 22 (2), 85-110.

SABARIEGO, M. (2002) La educación intercultural ante los retos del siglo XXI. Bilbao, Desclée de Brouwer.

Sales, A. y García, R. (1997) Programas de educación intercultural. Bilbao, Descleé de Brouwer.

Soriano Díaz, A. (2007) Los caminos de la educación cívico-moral. Un debate permanente. Teoría de la Educación, 19, 73-97.

Spaemann, R. (2000) Personas. Acerca de la distinción entre "algo"y "alguien". Barañain, eunsa.

Stavenhagen, R. (1996) La educación para un mundo multicultural, en Delors, J. (ed.) La educación encierra un tesoro. Madrid, Santillana-Ediciones UNESCO, 273-278.

TAYlor, C. (2002) Ética de la autenticidad. Barcelona, Paidós.

- (2012) Interculturalism or multiculturalism? Philosophy Social Criticism, 38 (4-5), 413-423.

Touriñán LóPEZ, J. M. (2009) El desarrollo cívico como objetivo. Una propuesta pedagógica. Teoría de la Educación. Revista Interuniversitaria, 21 (1), 129-159.

VILA Merino, E. S. (2005) Mundo de la vida y cultura: la educación como acción ética e intercultural. Teoría de la Educación. Revista Interuniversitaria, 17, 81-96. 